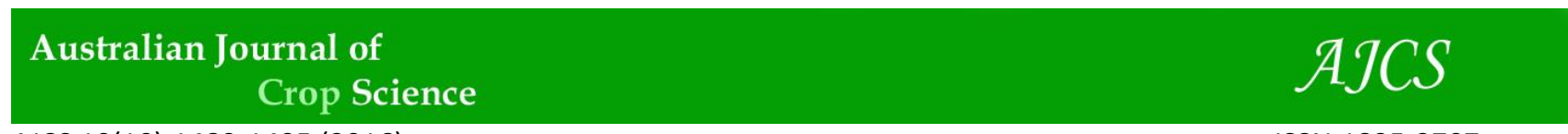

AJCS 10(10):1489-1495 (2016)

ISSN:1835-2707

DOI: 10.21475/ajcs.2016.10.10.p7867

\title{
Anatomical features of an African sorghum landrace adapted to flooded conditions
}

\author{
Sylvie Jaffuel*, Kirsten vom Brocke, Tuong-Vi Cao Hamadou, Audrey Dardou, Alain Vidal, Gilles \\ Trouche
}

CIRAD, UMR AGAP, F-34398 Montpellier, France

*Corresponding author: sylvie.jaffuel@cirad.fr

\begin{abstract}
This research aims to evaluate adaptation of two contrasting sorghum genotypes to flooding: a landrace from Cameroon described as a "floating sorghum" (Wulaga) and a typical dryland improved variety (Cirad437) from Burkina Faso. Anatomical and morphological features of the basal internodes were quantified in control conditions (drained pots) and long-term flooded conditions from the five-leaf stage for the entire cropping cycle. This study revealed that the Wulaga variety expressed aerenchyma in basal internodes in both control and flooded treatments (constitutive aerenchyma) whereas Cirad437 only developed aerenchyma in flooded conditions (inducible aerenchyma). The level of lignification and epidermis thickness of basal internodes was identical for the two varieties and the two treatments, suggesting that lignin does not contribute to the enhancement of a tight barrier against $\mathrm{O}_{2}$ losses. However, Cirad437 showed shorter and larger internodes in flooded conditions while Wulaga did not show any difference between the two conditions. Results indicate the existence of diversity in adaptive response to flooded conditions for the two varieties. Further studies on phenotypic traits associated with phenology, leaf traits, root traits and yield components, are needed to confirm these preliminary results and to explore a broader range of genetic diversity that could be used for future sorghum breeding programs designed for flood-prone environments.
\end{abstract}

Keywords: grain sorghum, flooding tolerance, aerenchyma, epidermis, internodes anatomy.

\section{Introduction}

Sorghum (Sorghum bicolor [L.] Moench) is a staple crop underlying the food security of rural populations in the semiarid regions of sub-Saharan Africa and South Asia. These areas are susceptible to recurrent climatic constraints, particularly erratic rainfall. In regard to West Africa, the Permanent Interstate Committee for drought control in the Sahel CILLS has pointed out an increasing number of extreme climatic phenomena in the context of climate change, including severe flooding with impact on natural ecosystems and agriculture (CILSS, 2010). Although adaptation of sorghum to dry environments is well recognized, few studies have been conducted on the capacity of sorghum to tolerate flooding stress. Within this context, we have studied a landrace from Cameroon locally known as "Wulaga" that is grown in temporarily flooded areas of the Logone valley in Northern Cameroon. Described as "floating sorghum" (Seignobos, 2000), Wulaga undergoes permanent submersion from the stage of 4-5 leaves until harvest, that is, from May-June to October. In order to investigate resistance to long-term flooding of the variety, a study was conducted to identify its anatomical and morphological traits.

The major effect of partial submergence for plants is oxygen deficiency, increased $\mathrm{CO}_{2}$ and the production of toxic substances $(\mathrm{Fe} 2+, \mathrm{Mn} 2+$ and $\mathrm{H} 2 \mathrm{~S}$ ) in the soil. This can rapidly reduce the redox potential of soils and cause severe plant damage, such as a reduction in plant growth and increased levels of $\mathrm{Al}, \mathrm{Mn}$, and $\mathrm{Na}$. In shoots, these levels are above critical toxicity concentrations (Setter et al., 2009). Hence, waterlogged soil and partial submergence will generally delay plant development, growth and metabolism, leading to significant yield losses, as shown by Anandan et al. (2015) for rice, Zaidi et al. (2004) for maize and Gomathi et al. (2014) for sugarcane. However, tolerance to flooded conditions in plants has also been identified. It requires an efficient mechanism for internal $\mathrm{O}_{2}$ transport from the aerial organs to the roots, as well as a capacity to reduce loss of oxygen from the roots so as to retain cellular oxygen. Improved internal aeration and oxygen distribution throughout the plant being subjected to flooded conditions is due to the synergy of certain anatomical traits, above all: (1) the intercellular spaces, i.e. aerenchyma, as described by Evans (2003) and Sauter (2013); and (2) lignified and suberized epidermis, which acts as a barrier against radial $\mathrm{O}_{2}$ loss (ROL) (Abiko et al., 2012). The barrier enhances the amount of $\mathrm{O}_{2}$ diffusing towards the root apex and enables the development of an aerobic rhizosphere around the root tip, thus enhancing root penetration into anaerobic substrates (Colmer, 2003).The development of aerenchyma not only boosts $\mathrm{O}_{2}$ movement to submerged tissues, but also promotes venting of gases into the atmosphere from these tissues. Generally two types of aerenchyma are distinguished: constitutive and inducible aerenchyma. According to Abiko and Obara (2014), constitutive aerenchyma develops as an integral part of ordinary root development whereas inducible aerenchyma develops in response to environmental stresses such as waterlogging, partial-submergence flooding, drought, or nutrient deficiency. Both aerenchyma types have been identified in rice (Yukiyoshi and Karahara, 2014) while 
several studies have facilitated the understanding of inducible aerenchyma formation in other rainfed crops, such as maize cultivation in waterlogged soils (Abiko et al., 2012). In many upland crops the major type of aerenchyma is also inducible (Colmer and Voesenek, 2009). Physiological investigations have shown that aerenchyma formation can also result from stimulation by other factors such as ethylene, reactive oxygen species (ROS), calcium signalling, and enzymatic cell-wall degradation (Yamauchi et al., 2013 and 2014).

Most research on aerenchyma formation concern roots. Few studies have focused on internodes in submersion situations or with limited oxygen exchange between the atmosphere and the roots. Recently, Yang et al. (2012) demonstrated via the stems and leaf cortex of wild rice that lysigenous aerenchyma stores oxygen and transports it to plant organs suffering hypoxia. Gilbert et al. (2007) concluded that stalk aerenchyma is an important indicator for evaluating flooding tolerance in sugarcane. Even fewer studies have examined the response of sorghum to hypoxia stress as a result of flooding. In a soil submitted to flood during 9 days at three different development stages (fiveleaf, panicle initiation and anthesis), Orchard and Jessop (1984 and 1985) revealed an increase of root porosity and a reduction in root weight, but with little effect on yield. Reduced root systems and limited shoot growth have also been quantified for flooded sorghum over 21days, beginning at 12 days after planting (Pardales et al., 1991). When investigating the adaptive potential of sweet multipurpose sorghum varieties as a pre-rice crop, Promkhambut et al. (2010 and 2011) observed aerenchyma in the roots and air spaces by means of cross-sections of the stalk bases of both control and flooded plants. The presence of aerenchyma and/or exoderm (epidermis) stem lignification as mechanisms for flooding tolerance or tolerance to other abiotic stresses, including increased tolerance to drought or nutrient deficiency, has not yet been taken into account by sorghum breeding programs. Improved understanding of the anatomical and morphological responses of sorghum to flooding stress could help to develop strategies for sustaining high yields under these conditions.

The present study offers a preliminary anatomical and morphological description of the aforementioned Wulaga floating sorghum landrace in comparison with a "typical" improved dryland grain sorghum variety (Cirad437). The aim is to shed light on the responses of these two varieties when exposed to flooded conditions by focusing on the anatomical differences between these two varieties at the lowest stem internodes in submerged conditions.

\section{Results}

\section{Observation of aerenchyma at internode level}

Stem cross-sections confirmed the presence of aerenchyma under flooded conditions for the two varieties Cirad437 and Wulaga (Fig.1 and 2). Aerenchyma was also observed in Wulaga in the non-flooded treatment (control) whereas it was not for Cirad437. The analysis of variance showed significant effects for variety, treatment, internode position and varietyxtreatment interaction for aerenchyma thickness (Table 1).

In the flooded treatment, internodes of both varieties had similar aerenchyma widths (Table 2). The aerenchyma width progressively decreased from the lower and totally submerged internode (I1) towards the upper internode (I3) (Table 2).

\section{Lignification of epidermis}

Lignin stained by Fasga colouration appeared as the main molecule constitutive of the cell walls of the epidermis under the two treatments and for both varieties (Fig. 3). The absence of staining with Soudan red indicated there is no suberin at the epidermis internode level of both varieties.

The analysis of variance revealed significant effect only for the variety factor and the variety $\times$ treatment interaction for the thickness of epidermis (Table 1). Under the control conditions, Wulaga showed a somewhat thicker epidermis than the Cirad437 variety although not significant according to the Tukey-Kramer test at $\mathrm{p}=0.05$. This was also the case for the differences in epidermis thickness observed between the two treatments and among the three internode positions for both varieties. For mean internode, Cirad437 under control conditions demonstrated a thickness of epidermis significantly lower than those of other variety $\mathrm{x}$ treatment combinations (Table 2).

\section{Effect on morphological traits}

Flooded conditions had divergent effects on most of the morphological traits of both varieties. For Wulaga, flooding reduced the number of tillers from 4.5 to 3.3 per plant, but did not affect plant height and number, length or diameter of the three lowest internodes (Table 3). Contrasting results were observed for Cirad437, for which the flooding treatment had significant effect on all traits, except for the number of internodes and number of tillers (Table 3). Under flooded conditions, plants of Cirad437 were significantly shorter $(97 \mathrm{~cm}$ against $141 \mathrm{~cm})$ with a significant two-to-three fold reduction in the length of the basal internodes and an increase of internode diameter for I1 and I 2 positions. The panicles of Cirad 437 were also significantly smaller under the flooded conditions compared to the control conditions.

\section{Discussion}

Our study revealed differences in internodes anatomy and morphological traits between the "floating" variety Wulaga and the "dryland variety" Cirad437 when submitted to longterm flooded conditions.

The study has firstly highlighted the presence of aerenchyma in internodes of both varieties when subjected to flooded conditions. Secondly, in the case of the Wulaga variety, this aerenchyma is also present under non-flooded conditions, and thus can be considered as constitutive, whereas Cirad437 develops an aerenchyma only under flooded conditions, and can therefore be considered as inducible aerenchyma. The latter develops in response to environmental factors and reveals the adaptive capacity of this variety to tolerate flooding stress. Our observations confirm the views of Promkhambut et al. (2011), who suggested (without showing any evidence) the presence of aerenchyma in the base of the stalks for two sweet sorghum varieties in flooded conditions.

At the root level, a constitutive development of aerenchyma has been previously suggested by Steffens et al. (2011) and Yukiyoshi and Karahara (2014) for rice, Mano and Omori (2013) for teosinte, and Garthwaite et al. (2003) for wild barley. But while most of this literature presents data for aerenchyma development in roots, our study reveals an aerenchyma development in stalks. A constitutive aerenchyma, as identified for Wulaga, had been previously 
Table 1. Summary statistics of analysis of variance for aerenchyma and epidermis thickness.

\begin{tabular}{|c|c|c|c|c|c|c|}
\hline \multirow[t]{2}{*}{ Source of variation } & \multicolumn{3}{|c|}{ Aerenchyma thickness } & \multicolumn{3}{|c|}{ Epidermis thickness } \\
\hline & $\mathrm{DF}$ & F-value & ProbF & $\mathrm{DF}$ & F-value & ProbF \\
\hline Variety & 1 & 14.43 & 0.0006 & 1 & 6.45 & 0.0162 \\
\hline Treatment & 1 & 31.60 & $<0.0001$ & 1 & 0.22 & 0.6449 \\
\hline PsInternode & 2 & 5.34 & 0.01 & 2 & 1.81 & 0.1795 \\
\hline Variety $\times$ PsInternode & 2 & 0.25 & 0.7810 & 2 & 0.19 & 0.8294 \\
\hline Treatment $\times$ PsInternode & 2 & 1.33 & 0.2786 & 2 & 0.83 & 0.446 \\
\hline Variety $\times$ Treatment & 1 & 34.78 & $<0.0001$ & 1 & 6.05 & 0.0197 \\
\hline Variety $\times$ Treatment $\times$ PsInternode & 2 & 1.94 & 0.1646 & 2 & 0.43 & 0.6567 \\
\hline
\end{tabular}
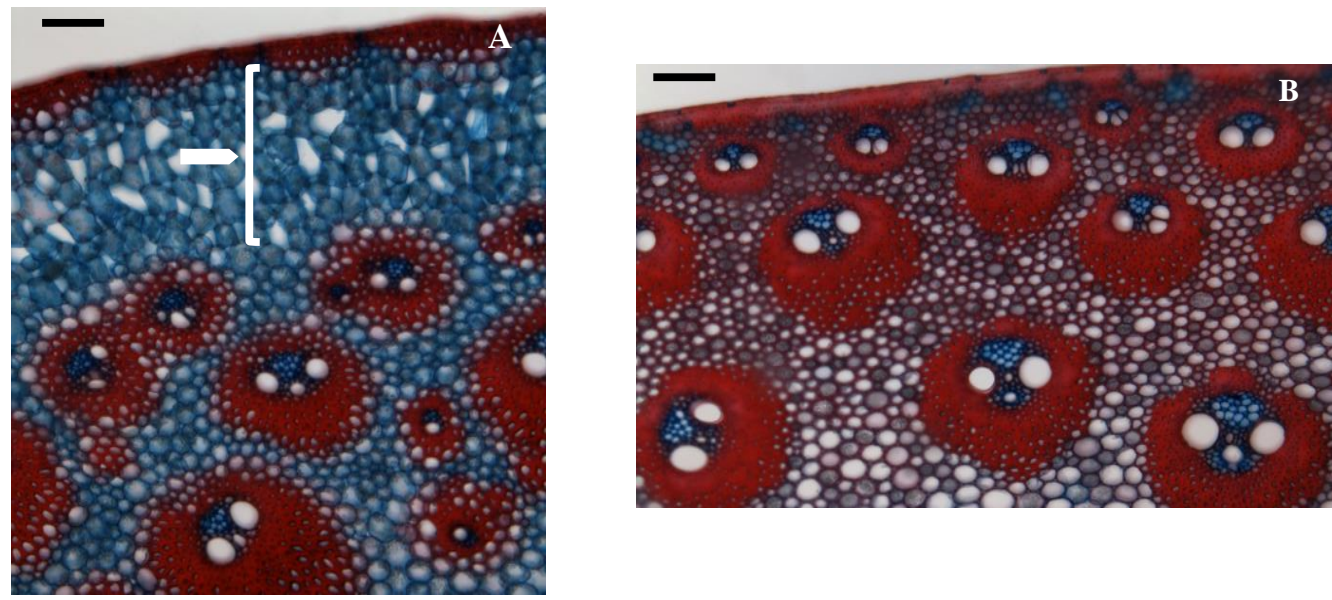

Fig 1. Comparison of internode (I1) stem cross sections of CIRAD 437 stained with Fasga and viewed under white light. The white bar and the arrow indicate aerenchyma between epidermis and cortical parenchyma under flooded conditions (A) but absent under

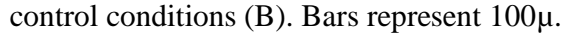

Table 2. Mean thickness $(\mu \mathrm{m})$ of aerenchyma (AER) and epidermis (EPI) measured for three internodes for two sorghum varieties grown under flooded and non-flooded (control) conditions. $\mathrm{I} 1=$ basal internode of the main stem; $\mathrm{I} 2=$ second internode of the main stem; I3 =third upper flooded internode.

\begin{tabular}{lcccccccccc}
\hline Trait & Variety & Treatment & I1 & & I2 & I3 & \multicolumn{2}{c}{ Mean } \\
\hline AER $(\mu \mathrm{m})$ & Cirad437 & Control & 0 & $\mathrm{~d}$ & 0 & $\mathrm{~d}$ & 0 & $\mathrm{~d}$ & 0 & $\mathrm{~b}$ \\
& & Flooded & 388 & $\mathrm{a}$ & 295 & $\mathrm{abc}$ & 182 & $\mathrm{c}$ & 288 & $\mathrm{a}$ \\
& Wulaga & Control & 294 & $\mathrm{abc}$ & 234 & $\mathrm{abc}$ & 173 & $\mathrm{c}$ & 234 & $\mathrm{a}$ \\
& & Flooded & 377 & $\mathrm{ab}$ & 221 & $\mathrm{bc}$ & 205 & $\mathrm{bc}$ & 276 & $\mathrm{a}$ \\
\hline EPI $(\mu \mathrm{m})$ & Cirad437 & Control & 49.7 & $\mathrm{a}$ & 39.1 & $\mathrm{a}$ & 35.1 & $\mathrm{a}$ & 40.6 & $\mathrm{~b}$ \\
& & Flooded & 48.2 & $\mathrm{a}$ & 55.4 & $\mathrm{a}$ & 51.0 & $\mathrm{a}$ & 51.5 & $\mathrm{a}$ \\
& \multirow{2}{*}{ Wulaga } & Control & 66.5 & $\mathrm{a}$ & 61.0 & $\mathrm{a}$ & 52.6 & $\mathrm{a}$ & 60.0 & $\mathrm{a}$ \\
& & Flooded & 56.7 & $\mathrm{a}$ & 54.9 & $\mathrm{a}$ & 42.6 & $\mathrm{a}$ & 52.5 & $\mathrm{a}$ \\
\hline
\end{tabular}

Note: $\mathrm{n}=10$ measurements on each internode; means followed by the same letter are not significantly different $(\mathrm{p}=0.05)$.
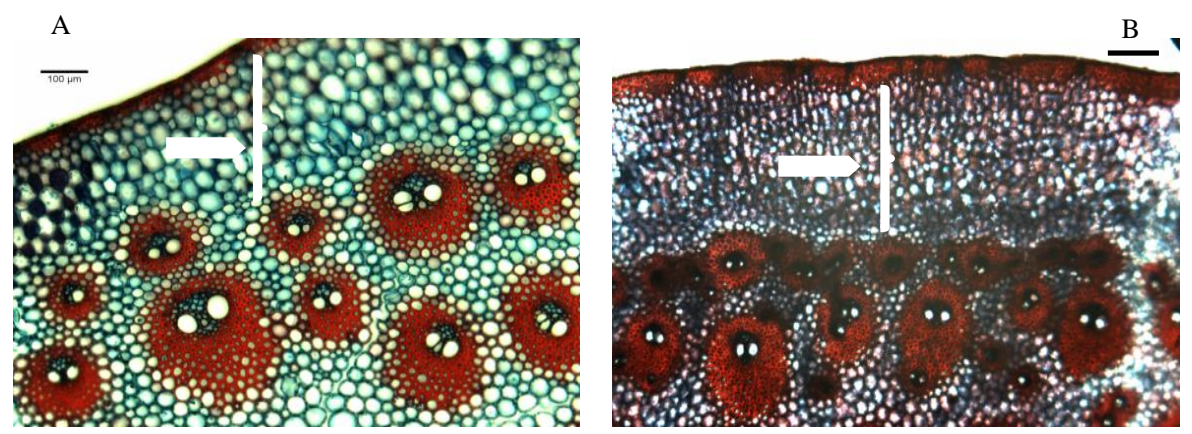

Fig 2. Comparison of internode (I1) stem cross sections of Wulaga stained with Fasga and viewed under white light. The white and the arrow indicate aerenchyma between epidermis and cortical parenchyma under flooded (A) and control conditions (B). Bars represent $100 \mu$ 
Table 3. Comparison of means $(n=4)$ for internodes number, tiller number, height of the main stem, length and diameter of the first three submerged internodes (from the basal =I1 to the upper zone= I3) for the Cirad437 and Wulaga varieties grown in control and flooded conditions.

\begin{tabular}{|c|c|c|c|c|c|c|c|c|c|c|}
\hline \multirow{2}{*}{ Variety } & \multirow{2}{*}{ Treatment } & \multirow{2}{*}{$\begin{array}{l}\text { Internode } \\
\text { number }\end{array}$} & \multirow{2}{*}{$\begin{array}{l}\text { Height } \\
(\mathrm{cm})\end{array}$} & \multirow{2}{*}{$\begin{array}{l}\text { Tiller } \\
\text { number }\end{array}$} & \multicolumn{3}{|c|}{ Internode length (mm) } & \multicolumn{3}{|c|}{ Internode diameter $(\mathrm{mm})$} \\
\hline & & & & & I1 & $\mathrm{I} 2$ & I3 & I1 & $\mathrm{I} 2$ & I3 \\
\hline \multirow{2}{*}{ Cirad437 } & Control & $13.0 \mathrm{a}$ & $141.3 \mathrm{a}$ & $2.8 \mathrm{a}$ & $77.5 \mathrm{a}$ & $58.0 \mathrm{a}$ & $48.4 \mathrm{a}$ & $18.1 \mathrm{~b}$ & $17.2 \mathrm{~b}$ & $16.4 \mathrm{a}$ \\
\hline & Flooded & $13.0 \mathrm{a}$ & $96.8 \mathrm{~b}$ & $2.8 \mathrm{a}$ & $33.0 \mathrm{~b}$ & $28.3 \mathrm{~b}$ & $17.4 \mathrm{~b}$ & $20.8 \mathrm{a}$ & $19.8 \mathrm{a}$ & $16.8 \mathrm{a}$ \\
\hline \multirow{2}{*}{ Wulaga } & Control & $14.0 \mathrm{a}$ & $125.3 \mathrm{a}$ & $4.5 \mathrm{a}$ & $21.7 \mathrm{a}$ & $31.6 \mathrm{a}$ & $45.0 \mathrm{a}$ & $21.8 \mathrm{a}$ & $20.8 \mathrm{a}$ & $21.3 \mathrm{a}$ \\
\hline & Flooded & $14.0 \mathrm{a}$ & $100.0 \mathrm{a}$ & $3.3 \mathrm{~b}$ & $12.5 \mathrm{a}$ & $31.5 \mathrm{a}$ & $36.7 \mathrm{a}$ & $18.0 \mathrm{a}$ & $20.1 \mathrm{a}$ & $20.3 \mathrm{a}$ \\
\hline
\end{tabular}

Note: Means followed by the same letter are not significantly different $(\mathrm{p}=0.05)$.
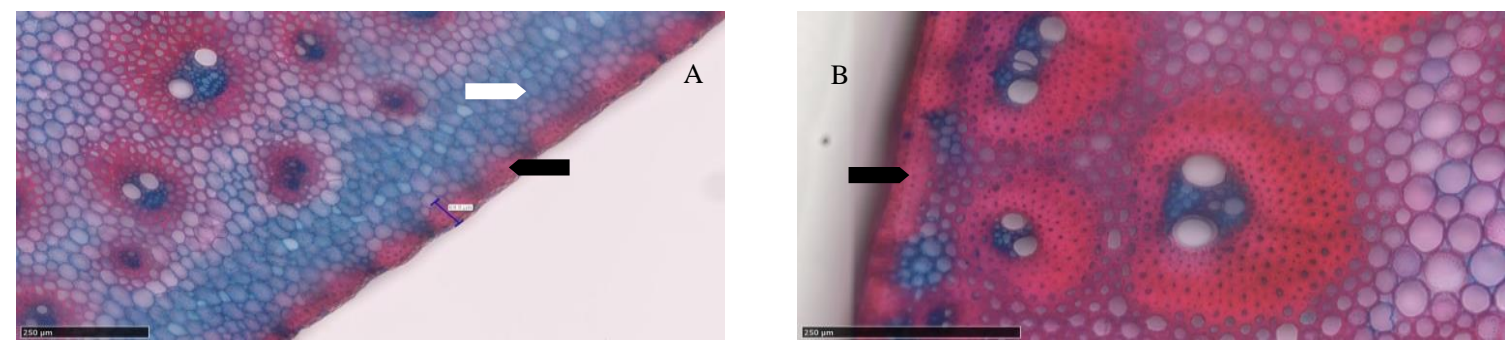

Fig 3. Comparison of internodes (I1) stem cross sections stained with Fasga and viewed under white light. Thickness of epidermis (black arrow) was calculated for the Wulaga (A) and Cirad437 (B) variety under control conditions. The white arrow indicates the presence of aerenchym. The red colour indicates the presence of Lignin in the cell walls epidermis and around vessels bundles. Bars represent $250 \mu \mathrm{m}$.

observed by Gilbert et al. (2007) in the stem bases of two sugarcane varieties.

Although we observed a significant decrease in aerenchyma thickness in the upper internode, this decreased thickness at the water-air transition zone could not be related to higher oxygen availability, as this development was also observed in the well-drained control treatment for Wulaga. Our study points to the existence of different mechanisms of aerenchyma formation in sorghum. A larger exploitation of sorghum genetic diversity could identify parental lines for breeding programs that target stress resistance such as flooding tolerance.

In order to understand the cellular mechanisms behind the formation of the two different aerenchyma types and their eventual control through environmental factors, we suggest carrying out a detailed study of the dynamics of aerenchyma formation in the plant stems and roots of a set of appropriate varieties, in both control and flooded situations. Preliminary analysis of the two varieties and the two treatments of the present study has already revealed aerenchyma in the roots. In rice roots, lignification of the epidermis along with suberin deposits in the exodermis has been described by Kotula et al. (2009) and Shiono et al. (2011) as being a barrier to Radial Oxygen Loss (ROL). Compared to Cirad437, Wulaga revealed a relatively thicker epidermis linked to lignin in the basal internodes for both treatments. However, the absence of significantly increased thickness under flooding indicates that reduced oxygen does not induce further lignification. A trend of increased lignification under flooding in Cirad437, on the other hand, may be an adaptive reaction to reduced oxygen in the soil. As speculated by Colmer (2003), an inducible barrier (lignin and suberin) to ROL may be of adaptive significance to plants inhabiting transiently flooded soils and/or contribute to the physiological plasticity that may enable some species (e.g. Oryza sativa) to grow in diverse environments ranging from drained to flooded soils. Shiono et al. (2011) stated that in rice roots, suberin increased prior to changes in lignin, suggesting that deposition of suberin is more important for
ROL barrier formation. As no suberin was detected in the present study at the internode level, the role of lignin in enhancing the barrier against $\mathrm{O}^{2}$ losses caused by increased flooding could not be confirmed. A future study focused on lignification during the development of internodes and its evolution in the sorghum stalks could ascertain if lignin presents a specific role in adaptation to flooded conditions.

As to be expected, plant development of the dryland sorghum variety Cirad 437 was adversely affected by flooded conditions, as highlighted by the significant reduction in plant height and internode length. This reduced plant height of Cirad437 confirms observations of Promhkambut et al. (2011), who, in studying two dryland sweet sorghum varieties, observed a 30 to $35 \%$ decrease in plant height under flooding stress. In another study, Promhkambut et al. (2010) underlined the negative impact of long-term flooding for 3 sweet and 1 forage sorghum varieties, which significantly reduces biomass production, increases the allocation of biomass to the roots, and reduces the leaf area. These authors showed in the same study that flooding stress significantly reduced the photosynthetic rate, as well as stomatal conductance and transpiration. Our study revealed that flooding causes an increase in the internode diameter of the lowest internodes, as was the case for Cirad437. The development of aerenchyma observed for this variety in flooded conditions probably explains this increase in internode diameter. In sugarcane, Gilbert et al. (2007) also observed an increase in internode diameter under flooded conditions, which was linked to the formation of stem aerenchyma.

Based on our preliminary results, flooding stress implies a regulation of plant carbon sources: sink relations in terms of photosynthesis, root-to-shoot ratio and, at the internode level, tissue composition to volume ratio. This regulation, of course, varies according to the sorghum genotype. These results must be validated by further studies that will closely examine related growth parameters (leaf and internode 
development, above ground and root yield), physiological traits (photosynthesis and respiration) and complementary anatomical observations in root and stem organs (in order to verify the start of aerenchyma development). This would provide the basis for a broader evaluation of a larger set of varieties representing relevant genetic diversity for sorghum in tropical flood-prone regions.

\section{Materials and Methods}

\section{Plant materials}

Two grain sorghum varieties were screened for anatomical features of the internodes under partially submerged conditions at the Lavalette campus of the CIRAD Institute in Montpellier, France $\left(43^{\circ} 35^{\prime} \mathrm{N}, 3^{\circ} 52^{\prime} \mathrm{E}\right)$. The first variety with the local name of Wulaga comes from Northern Cameroon where it is described as a "floating" sorghum; it is highly photoperiod-sensitive and belongs to the Durra race. The second variety, Cirad437 (also called Sariaso14) is a dryland improved variety developed in Burkina Faso by a CIRADINERA joint research program; this variety is slightly photoperiod-sensitive and belongs to the Caudatum race.

\section{Experimental design}

Both varieties were planted on May 25, 2011, separately in four 70 litres tubs filled with a mixture of $90 \%$ loam (half of Aus $\mathrm{N}^{\circ} 9$ and Aus $\mathrm{N}^{\circ}$ ) and $10 \%$ pozzolan. Also on May 25, twelve grains were sown per tub and thinned to four plants/tub approx. two weeks after emergence. From the fiveleaf stage, standing water (submerging a portion of the shoot and with all roots immerged) was permanently maintained in one tub for each variety and throughout the entire cropping cycle while the two further tubs for each variety were kept well irrigated but drained, thus serving as the control. The tubs were placed outdoors from May to October 2011 at the Lavalette CIRAD campus. Average daily temperatures ranged from 13 to $28^{\circ} \mathrm{C}$. Plant sampling was carried out between late September and early October when plant development stopped due to decreasing temperatures.

\section{Measurement of morphological traits and harvest}

Plants of Cirad437 were harvested at the dough grain stage (22/09/2011) for control treatment and again at the heading stage $(02 / 10 / 2011)$ for flooding treatment. The Wulaga plants were harvested at the vegetative state $(02 / 10 / 2011)$ for both treatments, due to the fact that this latter variety is highly photoperiod-susceptible. Just before harvest, the number of nodes and tillers were counted and the height of the main stem measured for each plant of each treatment.

\section{Histochemical detection and anatomical internodes measurements}

The first three internodes elongated from the base of the main stem (with a minimal length of $2 \mathrm{~cm}$ ) were harvested for anatomical study. By convention we considered the first internode (I1) as the lower on the stem. The length and diameter of each internode of three to four plants per variety and treatment were measured. After cleaning by repeated rinsing with distilled water, a $1 \mathrm{~cm}$ long segment in the middle part was cut. The internode segments were fixed in a buffer composed of phosphate $100 \mathrm{mM}$ (phosphate at $\mathrm{pH} 7.2$ ), with $1 \%(\mathrm{v} / \mathrm{v})$ glutaraldehyd, $2 \%(\mathrm{v} / \mathrm{v})$ paraformaldehyd and $1 \%$ (w/v) caffeine during $48 \mathrm{~h}$ at ambient temperature. For each segment, 20 serial stem cross sections, $80 \mu \mathrm{m}$ thick, were prepared with a vibratome (Microm HM $650 \mathrm{~V}$ ). Ten sections were stained overnight using a Safranin and Alcian blue solution (Fasga) diluted at 1/7. Alcian blue may be used as a blue stain for cellulose and is compatible with Safranin O, which colours lignin in red. The staining solution consisted of $14 \mathrm{ml}$ of Alcian blue ( $0.5 \%$ in ethanol), $2 \mathrm{ml}$ of Safranin O (1\% in water), $1 \mathrm{ml}$ of acetic acid, $30 \mathrm{ml}$ of glycerin, and $19.5 \mathrm{ml}$ of distilled water. After staining, the sections were rinsed twice for $5 \mathrm{~min}$ with distilled water and mounted on slides in glycerol (50/50). The Fasga staining coloured lignified tissues in red, whereas non-lignified or poorly lignified tissues were in blue.

Five other randomly chosen sections were stained using a solution of phloroglucinol (2\%), which was specific to $\mathrm{G}$ and $\mathrm{S}$ types of lignin, and then mounted on slides in glycerol (50/50). At the same time, one section per plant/internode was stained with Soudan red 7B specific to lipids (including suberin).

Prepared slides were observed with a DM4500 light microscope (Leica, Wetzlar, Germany) at different magnifications (5, 10 and 20), coupled with a Retiga 2000R Qimaging (Retiga, Surrey, Canada) digital camera using Velocity Acquisition 5.3.1 software (.com). Image analysis was performed using the open-source ImageJ freeware (http://rsbweb.nih.gov/ij/download.html; Ferreira \& Rasband 2010). For each magnification each slide was scanned and for each picture the thickness of epidermis and aerenchyma was measured.

\section{Statistical analysis}

In our study, the controlled factors of interest were variety (Wulaga and Cirad437), treatment (flooded and control) and internode position (I1, I2 and I3) as well as all their interactions. The four plants used for every Variety $\mathrm{x}$ Treatment combination were considered as replications. The anatomical measurements were obtained on several sections (9 to 15) per Internode position. These individual measurements were averaged per position for each Plant $\times$ Variety $\times$ Treatment combination. The means were then analysed with the GLM procedure based on the following models $(\mathrm{M})$ :

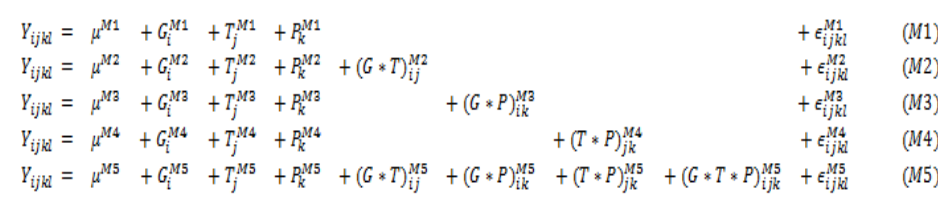

\begin{tabular}{|c|c|}
\hline With & \\
\hline$Y_{i j k l}$ & $\begin{array}{l}\text { being the observed value } \\
\text { of internode } k \text { on plant } l\end{array}$ \\
\hline$\mu^{M n}$ & $\begin{array}{l}\text { within variety } i \text { and treatment } j \\
\text { being the grand mean for model } \\
M n, n \text { varying from } 1 \text { to } 5\end{array}$ \\
\hline$G_{i}^{M n}$ & $\begin{array}{l}\in \text { being the varietal effect } i, i \\
\text { for model } M n\end{array}$ \\
\hline$T_{i}^{M n}$ & $\begin{array}{l}\text { being the treatment effect } \\
j, j \in\{\text { flooded, control }\} \\
\text { for model } M n\end{array}$ \\
\hline$P_{k}^{M n}$ & $\begin{array}{l}\text { being the internode position } \\
k, k \in\{\mathrm{E} 1, \mathrm{E} 2, \mathrm{E} 3\} \text {, for model mettre M2 }\end{array}$ \\
\hline
\end{tabular}




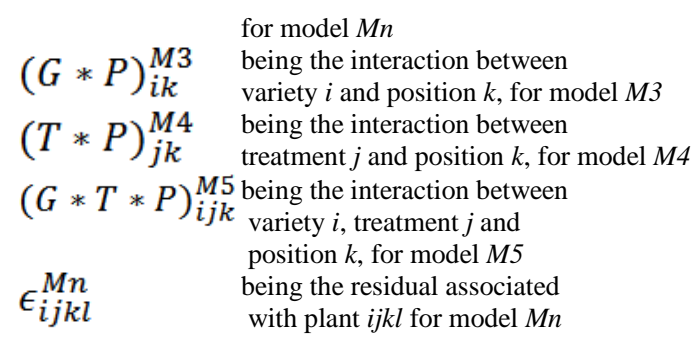

The main effects were tested using the residual mean square from M1 as the error term. Each two-way interaction was tested using the residual mean square from M1 to M4 respectively while the three-way interaction was tested using the residual mean square from M5.

For the variables aerenchyma and epidermis thickness, the Tukey-Kramer test (Tukey, 1953 and Kramer, 1956) for multiple comparisons was used to evaluate, on the one hand, the difference (at $\mathrm{p} \leq 0.05$ ) between Variety $\mathrm{x}$ Treatment combinations for each internode position and, on the other hand, between the same combinations for the average internodes. The same test was used to compare the flooded and control treatments for morphological traits within each variety.

\section{Conclusion}

Under both flooded and non-flooded conditions, a constitutive aerenchyma was identified in the basal internodes of the sorghum variety Wulaga, which points to an effective mechanism for oxygen exchange between aerial and underground plant organs. Nevertheless, it was shown that the variety Cirad437 developed an inducible internode aerenchyma under flooded conditions, which seems to contribute to hypoxia tolerance. For both varieties, variations observed under flooded conditions in thickness and lignification of the epidermis in the basal internode could not be interpreted as an adaptive or effective cell-wall barrier against $\mathrm{O}_{2}$ losses. Interestingly, the development of an aerenchyma by Cirad437 under flooded conditions was accompanied by a depressive effect on internode size and on growth. This trade-off needs to be further explored with a view to improving the adaptive value of inducible aerenchyma formation. In any case, this preliminary study showed the existence of highly adaptive diversity in the Wulaga sorghum variety in terms of flooding stress. Our study expands findings on aerenchyma as a key trait within flooding adaptation: from the root level to the basal internode level. While it is clear that aerenchyma plays a key role in the adaptation to flooding of sorghum and other plants, growth and metabolic processes need to be further analysed. This would allow quantification of the implications for plant production and the opportunity to explore a large range of diversity resources that could help to develop innovative cropping systems in marginal agro-ecological environments.

\section{Acknowledgements}

We thank Anthony McGowan for the English editing of the manuscript.

\section{References}

Abiko T, Kotula L, Shiono K, Malik AI, Colmer TD, Nakazono M (2012) Enhanced formation of aerenchyma and induction of a barrier to radial oxygen loss in adventitious roots of Zea nicaraguensis contribute to its waterlogging tolerance as compared with maize (Zea mays ssp. mays). Plant Cell Environ. 35(9):1618-1630.

Abiko T, Obara M (2014) Enhancement of porosity and aerenchyma formation in nitrogen-deficient rice roots. Plant Sci. 215-216:76-83.

Anandan A, Kumar Pradhan S, Kumar Das S, Behera L, Sangeetha G (2015) Differential responses of rice genotypes and physiological mechanism under prolonged deepwater flooding. Field Crop Res. 172:153-163.

CILSS (2010) Le Sahel face aux changements climatiques. Enjeux pour un développement durable. Numéro special. http://www.cilss.bf/IMG/pdf/specialChC.pdf

Colmer TD (2003) Long-distance transport of gases in plants: a perspective on internal aeration and radial oxygen loss from roots. Plant Cell Environ. 26:17-36.

Colmer TD, Voesenek ACJ (2009) Flooding tolerance: suites of plant traits in variable environments. Funct Plant Biol. 36:665-681.

Evans DE (2003) Aerenchyma formation. New Phytol. $161: 35-49$.

Garthwaite AJ, von Bothmer R, Colmer TD (2003) Diversity in root aeration traits associated with waterlogging tolerance in the genus Hordeum. Funct Plant Biol. 30:875889.

Gilbert RA, Rainbolt CR, Morris DR, Bennett AC (2007) Morphological responses of sugarcane to long-term flooding. Agron J. 99(6):1622-1628.

Gomathi R PN, Gururaja Rao PN, Chandran K, Selvi A (2014) Adaptive responses of sugarcane to waterlogging stress: An over view. Sugar Technol.17:1-14.

Kotula L, Ranathunge K, Schreiber L, Steudle E (2009) Functional and chemical comparison of apoplastic barriers to radial oxygen loss in roots of rice (Oryza sativa L.) grown in aerated or deoxygenated solution. J Exp Bot. 60:2155-2167.

Kramer CY (1956) Extension of Multiple Range Tests to Group Means with Unequal Numbers of Replications. Biometrics. 12:307-310.

Mano Y, Omori F (2013) Relationship between constitutive root aerenchyma formation and flooding tolerance in Zea nicaraguensis. Plant Soil. 370(1-2):447-460.

Orchard PW, Jessop RS (1984) The response of sorghum and sunflower to short-term waterlogging. I. Effects of stage of development and duration of waterlogging on growth and yield. Plant Soil. 81(1):119-132.

Orchard PW, Jessop RS (1985) The response of sorghum and sunflower to short-term waterlogging. III. Root growth effects. Plant Soil. 88:421-430.

Pardales JR, Kono Y, Yamauchi A (1991) Response of the different root system components of sorghum to incidence of waterlogging. Environ Exp Bot. 31(1):107-115.

Promkhambut A, Younger A, Polthanee A, Akkasaeng C (2010) Morphological and physiological responses of sorghum (Sorghum bicolor L. Moench) to waterlogging. Asian J Plant Sci. 9(4):183-193.

Promkhambut A, Polthanee A, Akkasaeng C, Younger A (2011) Growth, yield and aerenchyma formation of sweet and multipurpose sorghum (Sorghum bicolor L. Moench) as affected by flooding at different growth stages. Aust J Crop Sci. 5:954-965.

Sauter M (2013) Root responses to flooding. Curr Opin Plant Biol.16:282-286.

Seignobos C and Mandjek IO (2000) Atlas de la province de l'extrême Nord Cameroun. IRD MINREST_INC. 171p. 
Setter TL, Waters I, Sharma SK, Singh KN, Kulshreshtha N, Yaduvanshi NPS, Ram, PC, Singh BN, Rane J, McDonald G, Khabaz-Saberi H, Biddulph TB,Wilson, R, Barclay I, McLean R, Cakir M (2009) Review of wheat improvement for waterlogging tolerance in Australia and India: the importance of anaerobiosis and element toxicities associated with different soils. Ann Bot. 103(2):221-235.

Shiono K, Ogawa S, Yamazaki S, Isoda H, Fujimura T, Nakazono M, Colmer TD (2011) Contrasting dynamics of radial $\mathrm{O}_{2}$-loss barrier induction and aerenchyma formation in rice roots of two lengths. Ann Bot. 107:89-99.

Steffens B, Geske T, Sauter M (2011) Aerenchyma formation in the rice stem and its promotion by $\mathrm{H} 2 \mathrm{O} 2$. New Phytol 190: 369-378.

Tukey JW (1953) The Problem of Multiple Comparisons. H. I. Braun, ed., The Collected Works of John W. Tukey, volume 8, 1994, New York: Chapman \& Hall.

Yamauchi T, Shimamura S, Nakazono M, Mochizuki T (2013) Aerenchyma formation in crop species: A review. Field Crop Res.152: 8-16.

Yamauchi T, Watanabe K, Fukazawa A, Mori H, Abe F, Kawaguchi K, Oyanagi A, Nakazono M (2014) Ethylene and reactive oxygen species are involved in root aerenchyma formation and adaptation of wheat seedlings to oxygen-deficient conditions. J Exp Bot. 65(1):261-273.
Yang X, Li Y, Ren B, Ding L, Gao C, Shen Q, Guo S (2012) Drought-Induced Root Aerenchyma Formation Restricts Water Uptake in Rice Seedlings Supplied with Nitrate Plant Cell Physiol .53(3):495-504.

Yukiyoshi K, Karahara I (2014) Role of ethylene signalling in the formation of constitutive aerenchyma in primary roots of rice. AoB PLANTS 6: plu043. doi:10.1093/aobpla/plu043

Zaidi PH, Rafique S, Rai PK, Singh NN, Srinivasan G (2004) Tolerance to excess moisture in maize (Zea mays L.): susceptible crop stages and identification of tolerant genotypes. Field Crop Res 90(2-3):189-202. 